\section{Two cases of paradoxical hypothermia in a Sahara desert multi-stage ultramarathon}

\author{
Elizabeth A. Kaufman, ${ }^{1}$ Grant S. Lipman, ${ }^{1}$ \\ Louis J. Sharp, ${ }^{2,3}$ Brian J. Krabak ${ }^{4}$ \\ 'Department of Surgery, Division of \\ Emergency Medicine, Stanford University \\ School of Medicine, Stanford, CA; \\ 'Emergency Medicine Residency, \\ Presence Resurrection Medical Center, \\ Chicago, IL; ${ }^{3}$ Department of Emergency \\ Medicine, University of Illinois, Chicago, \\ IL; ${ }^{4}$ Department of Rehabilitation, \\ Orthopedics and Sports Medicine, \\ University of Washington and Seattle \\ Children's Hospital, Seattle, WA, USA
}

\section{Abstract}

Exertional hypothermia in a hot environment, a seemingly contradictory state, is a clinical presentation that has not been previously described in the medical literature. We present two cases of symptomatic hypothermia of $34-35^{\circ} \mathrm{C}\left(95^{\circ} \mathrm{F}\right)$ which resolved with ingestion of calories in otherwise healthy men competing in a multi-stage ultramarathon in the Sahara desert, Egypt 2012 with ambient temperatures of approximately $38-39^{\circ} \mathrm{C}(100$ $\left.102^{\circ} \mathrm{F}\right)$. Hypothermia is well documented in the medical literature as a presenting sign of hypoglycemia in both conscious and comatose patients. The mechanism by which hypoglycemia contributes to hypothermia is poorly understood, but may represent a compensatory response that reflects a decrease in energy demand during glucose deprivation. Wilderness medicine practitioners at endurance events should be cognizant of hypothermia as a potential presenting sign of hypoglycemia, as it can be empirically treated and rapidly reversed.

\section{Introduction}

An ultramarathon is any race longer than the standard $42.2 \mathrm{~km}$ (26.2 mile) marathon. ${ }^{1}$ These races are gaining popularity in North America, with an almost $10 \%$ increase in annual participants, and more than 69,000 finishers in $2013 .^{2}$ Competitors often run through a variety of terrain in inclement conditions with temperatures ranging from below freezing to greater than $40^{\circ} \mathrm{C}\left(104^{\circ} \mathrm{F}\right) .^{3}$ Although the majority of medical injuries encountered are often minor dermatologic and muscu- loskeletal issues, ${ }^{4,5}$ other serious and potentially debilitating conditions like exerciseassociated hyponatremia (EAH) ${ }^{6}$ or acute kidney injury ${ }^{1}$ have been reported as well.

Heat-related illnesses are a concern for any medical provider of ultramarathon runners with presentations that range from mild, usually self-limited heat exhaustion to potentially fatal heat stroke. ${ }^{7}$ Heat-related illness can present similarly to $\mathrm{EAH}^{8}$ or altitude illness, ${ }^{9}$ but a concomitant concern for, or presentation of hypothermia has not been discussed in recent practice guidelines. ${ }^{10}$ Exertional hypothermia was first documented in the temperate 1901 Boston Marathon in one runner who had consumed large amounts of alcohol, and in another who was exhausted more than the average..$^{11}$ However, as there are no reported cases of exertional hypothermia in hot conditions, a seemingly contradictory state, we introduce and define the term, paradoxical hypothermia. We present two cases of hypothermia in otherwise healthy men competing in a multi-stage ultramarathon in the Sahara desert, Egypt with ambient temperatures above $38^{\circ} \mathrm{C}\left(100.4^{\circ} \mathrm{F}\right)$.

\section{Case Report}

\section{Case \#1}

A 42 year old male with no significant past medical history and taking no medications was a participant in RacingThePlanet $^{\circledR} 250$ km (155 mile) 7 day, 6 stage ultramarathon in the Sahara desert, Egypt October, 2012. On the third stage the individual was observed at checkpoint $2,15.1 \mathrm{~km}$ (9.4 miles) from the start with ambient temperatures of approximately $39^{\circ} \mathrm{C}$ $\left(102.4^{\circ} \mathrm{F}\right)$, no wind or rain. He appeared fatigued with a pasty pale color, was walking slowly, and stated that he felt unwell and nauseous. He had been unable to tolerate his regular amount of water or electrolytes, and had resting heart rate of 84 beats per minute by palpitation. After 30 min of rest in the shade, the competitor continued on with the race. On arrival at checkpoint $3,23.5 \mathrm{~km}$ (14.7 miles) from the start, he continued to complain of fatigue and nausea. He was pale, with cool and diaphoretic skin, and complained of feeling cold. He had a resting heart of 80 beats per minute by palpitation, blood pressure of $116 / 75$ $\mathrm{mm} \mathrm{Hg}$ by manual monitor, with an axillary temperature of $34.4^{\circ} \mathrm{C}\left(94^{\circ} \mathrm{F}\right)$ (digital thermometer; The Kroger Co., Atlanta, GA, USA). He was provided with a $120 \mathrm{z}$ soda (150 cal; Pepsi Co., Sunnyvale, CA, USA) and placed in a support vehicle to rest. After ingesting the soda his symptoms of coldness, nausea and fatigue resolved, and he continued on the course. The participant ultimately finished the stage.
Correspondence: Elizabeth A. Kaufman, Department of Surgery, Division of Emergency Medicine, 300 Pasteur Drive, 94305-2200 Stanford, CA, USA.

Tel. +1.619.459.5648.

E-mail: ekaufman25@gmail.com

Key words: hypothermia, ultramarathon, hypoglycemia, multi-stage, desert.

Contributions: EAK, researched the topic, performed literature search, drafted the paper; GSL, researched the topic, edited, and gave the final approval of the version to be published; LJS and BJK, gathered data (LJS) and helped with revising the paper critically for important intellectual content.

Conflict of interests: the authors declare no potential conflict of interests.

Received for publication: 2 June 2014. Accepted for publication: 14 October 2014.

This work is licensed under a Creative Commons Attribution 3.0 License (by-nc 3.0).

(C) Copyright E.A. Kaufman et al., 2014

Licensee PAGEPress, Italy

Emergency Care Journal 2014; 10:4279

doi:10.4081/ecj.2014.4279

\section{Case \#2}

A 50 year old male with no significant past medical history and not taking any medications was a participant in the same Racing ThePlanet $^{\odot}$ event. The patient was seen on stage 2 at checkpoint 1 at 9 am $11.2 \mathrm{~km}$ (7.0 miles) from the start with an ambient temperature of approximately $38^{\circ} \mathrm{C}\left(100.4^{\circ} \mathrm{F}\right)$, with no wind or rain. He complained of feeling tired and had required frequent stops on the course, but felt better and continued to race after resting in the shade of the checkpoint. Further on the course he was seen several times hunched over, fatigued and apparently trying to catch his breath. He was stopped by a member of the medical team at $17 \mathrm{~km}$ (10.5 miles) from the start. He complained of feeling cold, with cool and moist skin. He appeared exhausted, without ataxia, and was leaning on the vehicle for support. He appeared agitated, repeatedly stating, I'm $\mathrm{OK}$, I can go on, and resisted efforts of medical assistance. His heart rate was 86 beats per min by palpitation, respiratory rate of 20 breaths per min, with an oral temperature of $35.1^{\circ} \mathrm{C}\left(95.3^{\circ} \mathrm{F}\right)$ (digital thermometer; The Kroger Co.). A repeat temperature several minutes later was $35.0^{\circ} \mathrm{C}\left(95.0^{\circ} \mathrm{F}\right)$. The medical team member used the same thermometer to check his own oral temperature, which was $36.2^{\circ} \mathrm{C}\left(97.1^{\circ} \mathrm{F}\right)$. The competitor was withdrawn from the race, and symptoms of cold and fatigue resolved with ingestion of food and rest. 


\section{Discussion}

There are little data that examine the incidence of hypothermia in geographical regions with a warm climate. ${ }^{12}$ Hypothermia is the condition when the body's temperature falls to $35^{\circ} \mathrm{C}\left(95^{\circ} \mathrm{F}\right)$ or below, ${ }^{13}$ that can present as a primary environmental disease or a complicating secondary state to a medical or traumatic condition. In hypothermic patients presenting to the emergency department, there is a $7 \%$ mortality with initial temperatures of mild hypothermia between 35 and $32.2^{\circ} \mathrm{C}$, and a $23 \%$ mortality when less that $32.2^{\circ} \mathrm{C} .{ }^{14}$ The primary effect of cooling is a decrease in metabolism, but the body's compensatory mechanisms are fully functional in cases of mild hypothermia, with ataxia, dysarthria and apathy commonly present. ${ }^{15}$ Factors that may contribute to the development of hypothermia range from environmental conditions such as wind, low temperatures, and moisture; to medical comorbidities such as diabetes, hypothyroidism, or substance abuse. ${ }^{16}$ It is highly unlikely that these two participants in a multi-stage ultramarathon in the hot and dry conditions of the Sahara desert presented with primary hypothermia. Rather, it is reasonable that it was a secondary manifestation to a disease such as hypoglycemia, a causative relationship that has been well described in hospital settings, but not previously in healthy ultramarathon runners.

The presenting symptoms and signs of hypoglycemia are well known to physicians. They may include anxiety, a sense of ill health, with feelings of detachment or apathy. There is often diaphoresis, ataxia, and if more severe, encephalopathy that may progress to coma and death if uncorrected. Hypothermia as a presenting sign of hypoglycemia was first described in $1964^{17}$ and has been most frequently described in diabetics, ${ }^{18}$ but also in those with varying oncologic processes, liver disease, and alcohol abuse with and without starvation states..$^{19}$ One of the early investigations into the association between hypothermia and hypoglycemia noted that $53 \%$ of consecutive hypoglycemic patients had hypothermia vs $5 \%$ of encephalopathy of other etiologies. $^{20}$

While the exact mechanism of hypothermia in hypoglycemia remains unclear, it is hypothesized that it may be due to increased heat dissipation from cutaneous vasodilation caused by disorder of the heat-regulating hypothalamus. ${ }^{19}$ Experimental evidence for this centrally mediated mechanism was initially described by Freinkel et al. in studies that injected a synthetic intracellular glucose inhibitor that produced hypoglycemia despite a serum euglycemic state. Healthy male volunteers' tem- peratures decreased $1.1^{\circ} \mathrm{C}\left(3.4^{\circ} \mathrm{F}\right)$ below baseline for $6 \mathrm{~h}$, indicating that hypothermia was triggered by intracellular glucopenia rather than by the availability of circulating glucose. ${ }^{21}$ Further animal studies found a 5-fold hypothermic response to injected centrally acting glucose inhibitor versus peripheral exposure, ${ }^{20}$ supporting the theory that thermoregulatory centers in the hypothalamus are thought to be both glucose and insulin sensitive. ${ }^{22}$ These studies suggest that hypothermia is a direct consequence of neuroglucopenia, and the decreased body temperature may be protective by preserving neuronal function while decreasing peripheral energy demands during times of glucose deprivation. ${ }^{18,19}$

Blood glucose levels in humans represent a balance between tissue uptake, hepatic glucose production - which in turn is dependent on glucose intake - glycogen reserves and gluconeogenesis from amino acids and their precursors. ${ }^{22}$ With exercise, skeletal muscles can increase their metabolic consumption by up to 20 times. $^{23}$ The ultramarathon participants in these 2 cases had high energy consumption and may have developed hypoglycemia due to increased tissue uptake from exercise, insufficient caloric intake, insufficient glycogen reserves, or a combination of all three. The initial hypoglycemia is likely what caused decreased neuronal intracellular glucose levels, which led to a disruption of the thermoregulatory centers in the hypothalamus. The rapid reversal of symptoms with intake of calories supports the supposition that the patients were hypoglycemic, as well as the proposed mechanism by which these athletes became hypothermic despite running through the heat of the Sahara desert.

Some limitations in this case report exist, namely the lack of measurement of the two ultra-runners' blood glucose concentration. Empirical evidence supports the assumption that a hypoglycemic state was present, and treatment of presumed hypoglycemia without definitive proof is supported by recent ultraendurance consensus guidelines. ${ }^{7}$ At this time the theorized pathophysiology of the documented hypothermia is unable to be definitively proven. A rectal temperature, which is considered the gold standard, ${ }^{7}$ would have provided a more accurate measurement as axillary and oral thermometers may underestimate core temperatures. Rectal thermometer probes (like glucometers) were not available at the time of the patient's care. Ultramarathon patients are often cared for in resource scarce wilderness settings, where a lack of adequate privacy and absence of multiple thermometers or glucometers per medical team members make empiric diagnoses and subsequent treatment a necessity.

\section{Conclusions}

Medical coverage of ultramarathons is usually provided by a team composed of multiple volunteers with differing levels of medical knowledge, ranging from doctors to medical technicians and nurses, often working in a wilderness environment. Awareness of the potential association between hypoglycemia and hypothermia in the at-risk population of endurance athletes is clinically important, as hypothermia may be the only sign that a patient is hypoglycemic, and obtaining an accurate differential diagnosis with scant diagnostic resources is often based on nothing more technologically advanced than a history and physical. In the cases of the two runners who suffered from mild hypothermic symptoms despite exercising in hot ambient temperatures, a state of paradoxical hypothermia, their rapidly reversal of symptoms after caloric ingestion supports hypoglycemia as the most reasonable mechanism. As treatment with simple carbohydrates is indicated in the field treatment of mild hypothermia ${ }^{7}$ and unlikely to harm a conscious hypothermic patient - it is an intervention available and easy to implement by both medical and lay-people. Furthermore, this case report highlights the need for medical providers of endurance runners to consider carrying a point-of-care glycemic monitor, which is light, inexpensive, and a useful diagnostic tool. As much of the data that exist regarding the mechanism of hypothermia in hypoglycemia are several decades old, awareness of exertional hypoglycemia in endurance athletes may confirm our observations and further research into this association would be potentially useful both for the endurance athlete and medical personnel.

\section{References}

1. Lipman GS, Krabak BJ, Waite BL, et al. A prospective cohort study of acute kidney injury in multi-stage ultramarathon runners: the Biochemistry in Endurance Runner Study (BIERS). Res Sports Med 2014;22:185-92.

2. UltraRunning. 2013 UltraRunning participation by the numbers. 2013. Available from: https://www.ultrarunning.com/featured/2013-ultrarunning-participation-bythe-numbers/

3. Krabak BJ, Waite B, Lipman GS. Injury and illnesses prevention for ultramarathoners. Curr Sports Med Rep 2013;12:183-9.

4. Jaworski CA. Medical concerns of marathons. Curr Sports Med Rep 2005;4:137-43. 
5. Krabak BJ, Waite B, Schiff MA. Study of injury and illness rates in multiday ultramarathon runners. Med Sci Sports Exerc 2011;43:2314-20.

6. Hoffman MD, Fogard K, Winger J, et al. Characteristics of 161-km ultramarathon finishers developing exercise-associated hyponatremia. Res Sports Med 2013;21:164-75.

7. Hoffman MD, Pasternak A, Rogers IR, et al. Medical services at ultra-endurance foot races in remote environments: medical issues and consensus guidelines. Sports Med 2014;44:1055-69.

8. Backer HD, Shopes E, Collins SL, Barkan H. Exertional heat illness and hyponatremia in hikers. Am J Emerg Med 1999;17:5329.

9. Ayus JC, Moritz ML. Exercise-associated hyponatremia masquerading as acute mountain sickness: are we missing the diagnosis? Clin J Sport Med 2008;18:383-6.

10. Lipman GS, Eifling KP, Ellis MA, et al. Wilderness Medical Society practice guidelines for the prevention and treatment of heat-related illness. Wild Environ Med 2013;24:351-61.

11. Blake JB, Larrabee RC. Observations upon long-distance runners. Boston Med Surg J 1903;148:195-206.

12. Elbaz G, Etzion 0, Delgado J, et al. Hypothermia in a desert climate: severity score and mortality prediction. Am J Emerg Med 2008;26:683-8.

13. Giesbrecht GG. Emergency treatment of hypothermia. Emergen Med 2001;13:9-16.

14. Danzl DF, Pozos RS, Auerbach PS, et al. Multicenter hypothermia survey. Ann Emerg Med 1987;16:1042-55.

15. Finnoff JT. Environmental effects on brain function. Curr Sports Med Rep 2008;7:2832.

16. Castellani JW, Young AJ, Ducharme MB, et al. American College of Sports Medicine position stand: prevention of cold injuries during exercise. Med Sci Sport Exer 2006;38:2012-29.

17. Kedes LH, Field JB. Hypothermia: a clue to hypoglycemia. New Engl J Med 1964;271: 785-7.

18. Tran C, Gariani K, Herrmann FR, et al. Hypothermia is a frequent sign of severe hypoglycaemia in patients with diabetes. Diabetes Metab 2012;38:370-2.

19. Hanson PJ, Loughridge LW, Mulhall BP, Packham DK. Hypothermia in hypoglycaemia. Brit Med J 1984;288:1212-3.

20. Strauch BS, Philip F, Baxter JD, Schimpff SC. Hypothermia in hypoglycemia. J Am Med Assoc 1969;210:345-6.

21. Freinkel N, Metzger BE, Harris E, et al. The hypothermia of hypoglycemia. Studies with 2-deoxy-D-glucose in normal human subjects and mice. New Engl J Med 1972;287:841-5.

22. Carter WP Jr. Hypothermia: a sign of hypoglycemia. JACEP 1976;5:594-5.

23. Maughan RJ, Shirreffs SM, Watson P. Exercise, heat, hydration and the brain. J Am Coll Nutr 2007;26:604-12. 